\title{
Job Market: Opening for Hospital Epidemiologist
}

There is a job opening for a hospital epidemiologist at the University of Tennessee, Memphis. The person who fills this position would be a member of the Division of Infectious Diseases in the Department of Medicine, and hospital epidemiologist at the Regional Medical Center at Memphis. The hospital epidemiology unit is located in contiguous space at the Regional Medical
Center. Resources are available to operate a comprehensive hospital epidemiology program.

The Regional Medical Center is affiliated with the University of Tennessee and has about 500 beds. The hospital has a level 1 trauma center, a bum center, a large level 3 neonatal intensive care unit, a high-risk obstetrics program, and several medical and surgical intensive care units.
Persons interested in this position should write to James B. Dale, MD; Division of Infectious Diseases; University of Tennessee, Memphis; 956 Court Ave. Room H-308; Memphis, TN 38163. Telephone: (901) 5285770, FAX (901) 5285854.

The University of Tennessee is an equal employment/ affirmative action/Title $\mathrm{C} /$ Section 504/ADA employer.

\section{Study of Natural Rubber Latex Reactions}

The Health Industry Manufacturers Association (HIMA) and the Centers for Disease Control and Prevention (CDC) are collaborating on a study of reactions to latex-containing products. The purpose of this study is to determine the prevalence and type of natural rubber latex reactions among workers at a wide variety of healthcare facilities and natural rubber latex manufacturing plants nationwide.

Reports of adverse reactions to products containing natural rubber latex have been increasing. Reports have been found in the medical literature and in the medical devices error/accident reporting system at the Food and Drug Administration. These reports and other published studies have identified healthcare workers and pediatric patients with myelodysplasia and other congenital malformations as high-risk groups for adverse reactions to products containing natural rubber latex. No such reports have occurred among natural rubber latex manufacturing workers.

Only two nationwide surveys of healthcare workers have been conducted to determine the prevalence of reactions to latex-containing products. One study by the Association of Operating Room Nurses, in collaboration with the CDC, surveyed operating room nurses (in press), and another surveyed army dentists (Berky ZT, et al. JAMA 1992;268:2695-2697). However, the prevalence of reactions to products containing natural rubber latex among all types of healthcare workers and among latex manufacturing workers is unknown. In particular, the relative incidence of reactions between these two groups and the incidence and relationship of localized and systemic reactions is unknown.

HIMA and CDC now are soliciting healthcare facilities and organizations for participation in this study. Participants in the study will be asked to administer a questionnaire to all workers in their facility or to a selected group within that facility. All responses will be anonymous and confidential. HIMA and CDC will furnish to each participating facility, upon request, the data gathered from that facility for its own use.

For more information on the project and participant responsibilities, please contact Siiri N. Bennett, MD, Hospital Infections Program, Mailstop A-07, Centers for Diseases Control and Prevention, 1600 Clifton Rd. NE, Atlanta, GA 30333, telephone (404) 639-1550, FAX (404) 639-3770; or Barry Page, Director, Environmental Technology Programs, 1200 G Street NW, Suite 400, Washington, DC 20005, telephone (202) 783-8700, FAX (202) $783-8750$.

Brief items of interest for the SHEA N ews or N ewsletter may be sent to C. Glen Mayhall, MD, SHEA, Newsletter Editor, Division of Infectious Diseases, Route 1092; The Former Shriner's Burns BIdg, Room 2-64B; University of Texas Medical Branch; Galveston, TX, 77555-1092; FM (409) 772-6527. Copy should be typed, double-spaced, and should not exceed five pages. 